\title{
Frequency of Musculoskeletal Pain and Associated Factors among Undergraduate Students
}

\author{
Muniba Mehmood Hasan', Uzair Yaqoob1 ${ }^{*}$, Sara Shaukat Ali1 ${ }^{1}$, Adeel Ahmed Siddiqui² \\ ${ }^{1}$ Sindh Medical College, Dow University of Health Sciences, Karachi, Pakistan \\ ${ }^{2}$ Dow University of Health Sciences, Karachi, Pakistan \\ Email: *ozair_91393@hotmail.com
}

How to cite this paper: Hasan, M.M., Yaqoob, U., Ali, S.S. and Siddiqui, A.A. (2018) Frequency of Musculoskeletal Pain and Associated Factors among Undergraduate Students. Case Reports in Clinical Medicine, 7, 131-145.

https://doi.org/10.4236/crcm.2018.72011

Received: December 29, 2017

Accepted: February 10, 2018

Published: February 13, 2018

Copyright $\odot 2018$ by authors and Scientific Research Publishing Inc. This work is licensed under the Creative Commons Attribution International License (CC BY 4.0).

http://creativecommons.org/licenses/by/4.0/

\begin{abstract}
Objective: To study and compare the prevalence of musculoskeletal pain in Medical and non-medical students and find out the specific factors associated with the occurrence of this pain. Methodology: This is a cross-sectional study from March-May 2017 where a total of 400 medical and 350 non-medical students were registered using a structured questionnaire made by modification of Nordic questionnaire. Characteristics of musculoskeletal pain were determined Pain was also graded by using a grading scale. Results: Mean age for medical and non-medical students was 21.36 and 20.97 respectively. The prevalence of musculoskeletal pain was higher among females. More data were collected from 2nd and 5th year of medical and 1st and 2nd year of non-medical students. High incidence was found in medical students with occurrence mostly in Neck. This frequency of musculoskeletal pain was quiet high during the last 7 days. The long study hours and use of computer/laptop were found to be greater among medical undergraduates but no significant association was found in medical unlike non-medical students. Majority of undergraduate students reported a normal BMI. Our study has found no co-relation of BMI with prevalence of pain. It was also observed that medical students with musculoskeletal pain spent more time on travelling when compared to non-medical. Association was found with the use of back packs. The study observed the level of many daily activities like exercise and outdoor sports etc. but no significant relation was found. Conclusion: Prevalence of musculoskeletal pain among undergraduate students is truly high, more so in medical students. Medical students have shown no association of studying for long hours and use of computer/laptop with musculoskeletal pain when compared to non-medical students. More studies should be done to know contributing factors of musculoskeletal pain among undergraduate students.
\end{abstract}




\section{Keywords}

Musculoskeletal Pain, Undergraduates, Medical Students, Non Medical Students, Neck Pain

\section{Introduction}

Musculoskeletal pain is one of the most frequent types of pain that affects the muscles, bones, joints, ligaments and tendons [1]. Musculoskeletal pain can be acute or chronic. Acute musculoskeletal pain can be severe, lasts for a short period of time and is predominantly due to local causes such as fractures, sprains, dislocations and infections [2]. In contrast, chronic musculoskeletal pain persists over a long period of time and is likely to be associated with cancer and arthritis [3]. Musculoskeletal problems are the most common reported complaints among health care professionals [4]. The principal aim of a medical school is to bring capable qualified doctors and provide better health status in society [5]. Medical students are more likely to be affected by increased workload in wards of hospitals, stress and long study hours during the period of their medical training [6].

The United Nations and World Health Organization (WHO) identified the burden of musculoskeletal conditions on individuals and brought this topic into focus [7]. According to the research published by WHO, low back pain and neck pain were recognized as number 1 and 4 respectively, among the leading causes of years lived with disability [8]. The leading cause of work interference in the US is musculoskeletal pain [9]. The burden of neck pain, shoulders pain and low back pain is notably increasing and therefore, nowadays millions of people in Europe have musculoskeletal pain [10]. The frequency of musculoskeletal pain is also high among many occupational groups of china [11]. One of the major causes of disability in UAE is the musculoskeletal diseases [12]. The trouble of persistent musculoskeletal pain is significantly important in young adults, making their lives more difficult and challenging [13].

A study in Malaysia showed that medical students with family history of musculoskeletal pain, history of trauma and those who were in the clinical years had more prevalence of musculoskeletal pain [14]. The burdensome curriculum of medical colleges, make medical students vulnerable to have sedentary life style and perhaps high risk of low back pain [15]. Low back pain was significantly associated with medical students of final year compared to 1st year students [16]. According to a study in China, the prevalence of musculoskeletal disorders was $67.6 \%$ occurring most frequently at the regions of lower back, neck and shoulders [17]. Bad posture positions, obesity, poor physical activity and heavy back packs were also associated with high risk of low back pain [18]. According to this study, the prevalence of musculoskeletal pain among Australian medical students was high, most commonly involving the neck followed by low back and shoulders [19]. A study in Saudi Arabia identified the neck pain was much 
common among female undergraduate students [20]. The research in Northern Queensland showed the frequency of low back pain was high among many occupational therapy students [21]. In Delhi, India, high mental pressure, depression and continuous workload were found higher among medical students with low back pain [22]. A research in Uttar showed that the frequency of neck pain among undergraduate medical students was much great [23]. A study conducted in Karachi, Pakistan, concluded that medical students has increased prevalence of low back pain associated with factors such as smoking and more usage of computer [24]. Low back pain, neck pain and shoulders pain appeared to be highest among health care professionals [21]. There are many possible factors contributing to increase frequency of musculoskeletal pain among medical students however not a single major factor has been identified.

In Pakistan, there has been few statistics of musculoskeletal pain among undergraduate students. It would be important for us to know the impact of risk factors such as trauma, family history of musculoskeletal pain, exercise and physical activity on the aggravation of musculoskeletal pain. Further, this study also examined the association of long study hours, computer use and travelling, smoking and caffeine intake on the degree of exacerbation of musculoskeletal pain. In this cross sectional study we are also expecting to see the increase in prevalence of musculoskeletal pain in medical students due to various factors like long study hours, hospital rotations, etc. Therefore, the aim of this study is to investigate the prevalence and possible risk factors of musculoskeletal pain in the medical and non-medical student population of Karachi.

\section{Methodology}

\subsection{Study Design}

Comparative cross-sectional study.

\subsection{Setting}

For medical students: different public sector Medical college campuses.

For non-medical students: different public sector Engineering and business college campuses.

\subsection{Duration}

March 2017 to My 2017.

\subsection{Sampling Technique}

Probability Convenient sampling.

\subsection{Sample Size}

Sample size was calculated using OpenEpi software. For the above mentioned objective i.e. to study the prevalence of musculoskeletal pain in Medical and non-medical students, the sample size came out to be 382 for medical students. 
[14] and 334 for non medical students at confidence interval of $95 \%$ having bound of error of 5\%. In order to decrease the margin of error we had a sample of 400 and 350 respectively.

\subsection{Sample Selection}

\section{Inclusion Criteria}

Those in 1st to final academic year of medical and engineering curriculum of study.

\subsection{Exclusion Criteria}

Those having Vitamin D deficiency.

Those having any joint disease.

\subsection{Study Variables}

Dependent variables:

Presence of musculoskeletal pain and Graded Chronic pain scale (GCPS) score of students.

\subsection{Independent Variables}

Gender, age, category of student, name of institute, academic year, height, weight, dominant hand, most common site of pain, pain relievers, referral to a doctor, hospitalization, school absence, pain during last 12 months, effect on activity, effect on sleep, pain during last 7 days, family history, past medical history, study hours, duration of computer/laptop usage, duration of sleep, exercise, playing outdoor sports, weight lifting, physical activities, house maintenance, smoking, drinking coffee, back packs, method of studying, driving, riding, usual mode of transport and average traveling time.

\subsection{Data Collection Procedure}

Data was collected through interviews by filling a proforma made by modification of standard Nordic questionnaire having variables including Socio-demographics, those related to pain and factors that might be associated with pain [25]. A total of 400 medical and 350 non-medical students were registered randomly after having informed consent using a structured questionnaire. A pilot study was conducted to assess the validity of questionnaire. The questionnaire was developed containing all relevant questions and modified with the help of previous studies. Participant was assured of confidentiality. He/She was assured that no information regarding the interviews and test results will be shared to any one and that this information will be used only for research purpose. He was also assured that the identity will not be disclosed at any point in time. Questionnaires were given an identification number. Data was entered twice and then cleaned for any missing variables. Data collection procedure was supervised by principal investigator. 


\subsection{Scales Included}

Graded Chronic pain scale (GCPS) was used for assessing the severity of pain [26].

\subsection{Data Analysis Plan}

Data was entered and analyzed in SPSS version 20 for analysis. Frequency and percentages were calculated for all variables, while mean and standard deviation for age, BMI, study hours, duration of computer/laptop usage, duration of sleep and traveling time. Variables like Gender, Academic Year, weight category according To BMI, duration of Study, duration of Computer/Laptop Use, duration of Sleep, duration of traveling and mode of transport were cross-tabulated against the presence of musculoskeletal pain. A p-value of 0.05 was considered as statistically significant.

\section{Result}

400 medical and 350 non medical students from different universities of Karachi participated in this cross sectional study. Mean age for medical students and non-medical students was $21.36 \pm 1.910$ and $20.97 \pm 1.876$ respectively. Socio-demographic data of medical and non medical students is shown in Table 1.

Table 2 shows high incidence of musculoskeletal pain in medical students (88.5\%) with highest occurrence in neck (19.3\%) followed by low back and legs. The incidence of musculoskeletal pain in non medical students was $64.9 \%$ with highest occurrence in neck (17.4\%) followed by low back and legs.

Almost $61.86 \%$ of medical students who reported musculoskeletal pain in the last 12 months had it in the past 7 days (Table 3 ). Similarly $56.82 \%$ of non medical students also reported pain in last 7 days.

Figure 1 and Figure 2 shows that pain was graded using graded chronic pain scale. Most medical students had grade 1 pain with a prevalence of $49 \%$ whereas in non medical students mostly reported grade 0 pain with a prevalence of $36 \%$.

According to Table 4 in both medical and non medical groups, female shows high percentage of musculoskeletal pain. When gender was considered, musculoskeletal pain in male and female medical students was $25.42 \%$ and $74.5 \%$ respectively whereas for non medical students it was 39.20 and $60.79 \%$ respectively. Medical students with musculoskeletal pain showed longer daily hours of study than non medical students. Use of laptop/computer was found more in Medical students but was not significantly associated with pain, whereas significant association was found in non-medical students ( $p$-Value $<0.001$ ). It was also observed that medical students travel more than non medical students. Students who used to travel more than one hour had significant increase in musculoskeletal pain in their body ( $\mathrm{p}$-Value $<0.05$ ). In medical students the musculoskeletal pain was slightly higher in students posted to clinical rotation but no significant relation was found ( $\mathrm{p}$-Value 0.346 ). Majority of medical and non medical students with musculoskeletal pain had either normal weight or was 
Table 1. Socio-Demographics.

\begin{tabular}{|c|c|c|c|c|}
\hline & \multicolumn{2}{|c|}{$\begin{array}{c}\text { Medical } \\
\text { Students }(n=400)\end{array}$} & \multicolumn{2}{|c|}{$\begin{array}{c}\text { Non-Medical } \\
\text { Students }(n=350)\end{array}$} \\
\hline & Frequency & Percentage & Frequency & Percentage \\
\hline \multicolumn{5}{|l|}{ Gender } \\
\hline Female & 298 & 74.5 & 201 & 57.4 \\
\hline Male & 102 & 25.5 & 149 & 42.6 \\
\hline \multicolumn{5}{|l|}{ Age $(21.36 \pm 1.910)$} \\
\hline $18-20$ & 166 & 41.5 & 171 & 48.9 \\
\hline $21-23$ & 167 & 41.8 & 145 & 41.4 \\
\hline $24-26$ & 67 & 16.8 & 34 & 9.7 \\
\hline \multicolumn{5}{|l|}{ Name Of Institute } \\
\hline DUHS & 350 & 87.5 & 0 & 0 \\
\hline Ziauddin University Hospital & 50 & 12.5 & 0 & 0 \\
\hline Karachi University & 0 & 0 & 139 & 39.7 \\
\hline SZABIST & 0 & 0 & 45 & 12.9 \\
\hline NED & 0 & 0 & 75 & 21.4 \\
\hline IBA & 0 & 0 & 91 & 26 \\
\hline \multicolumn{5}{|l|}{ Academic Year } \\
\hline 1st Year & 19 & 4.8 & 118 & 33.7 \\
\hline 2nd Year & 152 & 38 & 106 & 30.3 \\
\hline 3rd Year & 35 & 8.8 & 51 & 14.6 \\
\hline 4 th year & 44 & 11 & 63 & 18 \\
\hline 5th Year & 150 & 37.5 & 12 & 3.4 \\
\hline \multicolumn{5}{|l|}{ Basal Metabolic Index $(21.4672 \pm 4.25)$} \\
\hline Under Weight & 86 & 21.5 & 91 & 27.3 \\
\hline Normal Weight & 206 & 51.5 & 200 & 60.1 \\
\hline Overweight & 47 & 11.8 & 27 & 8.1 \\
\hline Obese & 15 & 3.8 & 15 & 4.5 \\
\hline Missing & 46 & 11.5 & 17 & 4.9 \\
\hline \multicolumn{5}{|l|}{ Right Handed Or Left Handed } \\
\hline Right Handed & 348 & 87 & 322 & 92 \\
\hline Left Handed & 52 & 13 & 28 & 8 \\
\hline
\end{tabular}

under weight so increase BMI had no co relation with increase prevalence of musculoskeletal pain. Another factor that may have contributed to increased prevalence of musculoskeletal pain particularly neck and low back pain was the usage of back packs among them. Almost $88.13 \%$ of medical students and $84.14 \%$ of non medical students who had musculoskeletal pain were using back packs.

The study also observed the level of many daily activities including daily exercise, outdoor sports and weight lifting, house work, cigarette smoking, coffee 
Table 2. Musculoskeletal pain.

\begin{tabular}{ccccc}
\hline & \multicolumn{2}{c}{ Medical Students } & \multicolumn{2}{c}{ Non-Medical Students } \\
\cline { 2 - 5 } & Frequency & Percentage & Frequency & Percentage \\
\hline In the Last 12 months & & & & \\
\hline Yes & 354 & 88.5 & 227 & 64.9 \\
No & 46 & 11.5 & 123 & 35.1 \\
\hline Usual Site & 61 & & & \\
Neck & 7 & 3.7 & 61 & 26.9 \\
Left shoulder & 13 & 5.1 & 7 & 3.1 \\
Right Shoulder & 22 & 10.7 & 13 & 5.7 \\
Upper Back & 56 & 21.2 & 22 & 9.7 \\
Low Back & 1 & 0.6 & 56 & 24.7 \\
Elbows & 7 & 3.7 & 1 & 0.4 \\
Wrist/Hands & 4 & 5.9 & 7 & 3.1 \\
Thighs/Hips & 52 & 21.2 & 52 & 1.8 \\
Legs & 4 & 6.2 & 4 & 22.9 \\
Ankles/feet & & & 1.8 \\
\hline
\end{tabular}

Table 3. Pain during the Last 7 days.

\begin{tabular}{ccccc}
\hline & \multicolumn{2}{c}{ Medical Students $(\mathrm{n}=400)$} & \multicolumn{2}{c}{ Non-Medical Students $(\mathrm{n}=350)$} \\
\cline { 2 - 5 } & Frequency & Percentage & Frequency & Percentage \\
\hline Yes & 219 & 61.9 & 129 & 56.8 \\
No & 135 & 38.1 & 98 & 43.2 \\
\hline
\end{tabular}
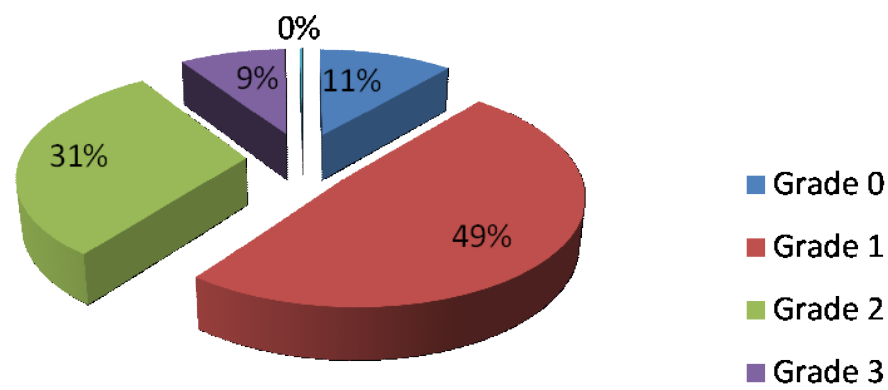

Grade 4

Fiugre 1. GCPS Grading (Medical Students).

drinking and study method but no significant relation was found with these factors. Family history and past medical history was also found in a lot of patients but there was no positive association.

\section{Discussion}

This is the study that reports frequency of musculoskeletal pain and associated factors among undergraduate students. In this cross sectional study, data showed 


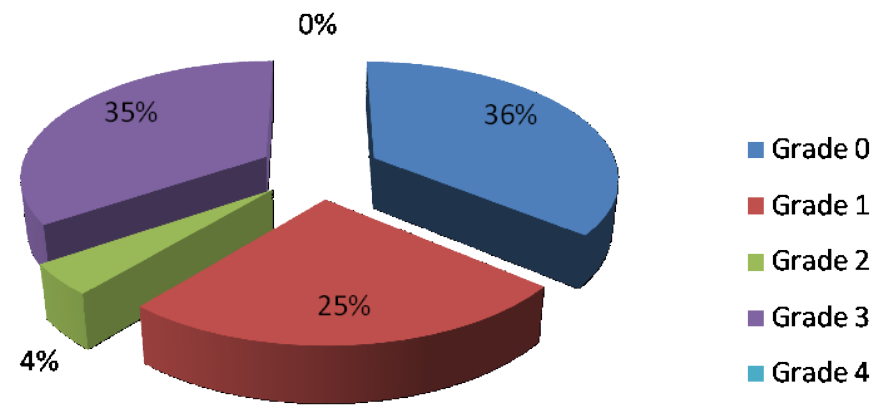

Fiugre 2. GCPS grading (Non-Medical Students).

that more than half of the medical (88.5\%) and non-medical (64.9\%) undergraduate students have been reported for musculoskeletal pain in the previous 12 months. On the other hand, this prevalence of musculoskeletal pain among medical students when compared with Malaysian medical students (65.1\%) was much higher [14]. In our study findings also revealed the prevalence of pain at any time during last 7 days was $61.8 \%$ in medical and $56.82 \%$ in non-medical students.

In our study the most common site of the musculoskeletal pain reported by both medical and non-medical groups was neck followed by lower back and legs. According to a study in Australia, the most frequent site of musculoskeletal pain in medical undergraduates was neck [19]. One study of Thailand also concluded that the neck pain was much common among undergraduate students (46\%) and there are many risk factors which are responsible for persistent neck pain [27]. However, a research in China and Malaysia showed the most common site affected by musculoskeletal pain among medical undergraduates was lower back followed by the neck [14] [17]. Neck pain is generally more common among women and countries with higher income [28]. According to our research, female undergraduates of both medical and non-medical groups were found to have a higher prevalence of neck pain compared to male students. There are many studies which showed the occurrence of neck pain symptoms were more frequent among undergraduate female students [29] [30]. However, a study in Australia showed the prevalence of pain was high among male undergraduates [31].

Redcliff reported medical students have increased pressure of work load especially during preparation for examinations and acquiring professional knowledge, this period was highlighted as the most stressful phase of medical training [32]. The neck pain has become a rising problem among the students of universities [20]. A Nigerian study showed a significant number of students had episodes of neck pain after admission into the university than before [33]. Recent survey showed static postures such as during prolonged computer work, reading and writing increased the risk of neck pain among undergraduates [34]. Different risk factors can be associated with musculoskeletal pain however, statistical analysis of our research showed that use of computer/laptop and long study 
Table 4. Comparison of musculoskeletal pain in medical and non-medical students.

\begin{tabular}{|c|c|c|c|c|c|c|}
\hline & \multicolumn{2}{|c|}{$\begin{array}{c}\text { In Medical } \\
\text { Students }(n=400)\end{array}$} & \multirow{2}{*}{ p-Value } & \multicolumn{2}{|c|}{$\begin{array}{c}\text { In Non-Medical } \\
\text { Students }(\mathrm{n}=350)\end{array}$} & \multirow[t]{2}{*}{$p$-Value } \\
\hline & Yes & No & & Yes & No & \\
\hline \multicolumn{7}{|l|}{ Gender } \\
\hline Female & 264 & 34 & 0.923 & 138 & 63 & 0.084 \\
\hline Male & 90 & 12 & & 89 & 60 & \\
\hline \multicolumn{7}{|c|}{ Weight According To BMI } \\
\hline Underweight & 79 & 7 & & 59 & 32 & \\
\hline Normal Weight & 186 & 20 & 0.816 & 127 & 73 & 0.952 \\
\hline Overweight & 41 & 6 & & 16 & 11 & \\
\hline Obese & 13 & 2 & & 10 & 5 & \\
\hline \multicolumn{7}{|l|}{ Academic Year } \\
\hline 1st Year & 15 & 4 & \multirow{5}{*}{0.346} & 66 & 118 & \multirow{5}{*}{0.1} \\
\hline 2nd Year & 136 & 16 & & 75 & 106 & \\
\hline 3rd Year & 31 & 4 & & 28 & 51 & \\
\hline 4th Year & 36 & 8 & & 48 & 63 & \\
\hline 5th Year & 136 & 14 & & 10 & 12 & \\
\hline \multicolumn{7}{|l|}{ Duration of Study } \\
\hline$<4$ Hours/day & 171 & 22 & \multirow{4}{*}{0.575} & 138 & 78 & \multirow{4}{*}{$<0.001$} \\
\hline 4 - 7 Hours/day & 107 & 15 & & 57 & 22 & \\
\hline $8-11$ Hours/day & 50 & 8 & & 30 & 10 & \\
\hline$>11$ Hours/day & 26 & 1 & & 2 & 13 & \\
\hline \multicolumn{7}{|l|}{$\begin{array}{c}\text { Duration of } \\
\text { Computer/Laptop Use }\end{array}$} \\
\hline$<4$ Hours/day & 251 & 41 & \multirow{4}{*}{0.06} & 150 & 102 & \multirow{4}{*}{$<0.001$} \\
\hline 4-7 Hours/day & 59 & 4 & & 42 & 7 & \\
\hline 8-11 Hours/day & 28 & 1 & & 25 & 7 & \\
\hline$>11$ Hours/day & 16 & 0 & & 10 & 7 & \\
\hline \multicolumn{7}{|l|}{ Duration of Sleep } \\
\hline$<4$ Hours/day & 45 & 15 & \multirow{4}{*}{0.003} & 23 & 9 & \multirow{4}{*}{0.001} \\
\hline 4 - 7 Hours/day & 156 & 12 & & 91 & 36 & \\
\hline 8-11 Hours/day & 139 & 17 & & 107 & 62 & \\
\hline$>11$ Hours/day & 14 & 2 & & 6 & 16 & \\
\hline \multicolumn{7}{|l|}{ Duration of traveling } \\
\hline$<60$ Minutes/day & 151 & 29 & \multirow{4}{*}{$<0.001$} & 110 & 54 & \multirow{4}{*}{0.03} \\
\hline $60-180$ Minutes/day & 185 & 12 & & 93 & 65 & \\
\hline $180-240$ Minutes/day & 13 & 1 & & 19 & 4 & \\
\hline$>240$ Minutes/day & 5 & 4 & & 5 & 0 & \\
\hline \multicolumn{7}{|l|}{$\begin{array}{c}\text { What mode of transport } \\
\text { you usually use for } \\
\text { traveling? }\end{array}$} \\
\hline Car & 154 & 17 & \multirow[t]{4}{*}{0.19} & 57 & 35 & \multirow[t]{3}{*}{0.09} \\
\hline Bike & 25 & 4 & & 63 & 45 & \\
\hline Bus & 113 & 21 & & 63 & 30 & \\
\hline Auto Rickshaw & 62 & 4 & & 44 & 13 & \\
\hline
\end{tabular}


hours were high among medical students when compared with nonmedical students but it was not significantly associated with pain. In contrary to our research, a study showed that medical students are more likely to develop musculoskeletal pain because of more use of computer screen for their work [24]. A study in Saudi Arabia concluded that medical students for their academic activities spend more time in sitting position for reading, writing and computer use [20]. One study in Uttar found that the most common cause of neck pain among medical students was prolonged reading followed by use of computers and prolonged writing [23]. However a study in Malaysia showed no significant association of musculoskeletal pain with hours of computer use in a day and type of computer use [35]. According to our research, studying on bed was found to be significantly associated with musculoskeletal pain among undergraduate students. A study reported that a poor sitting position was associated with neck pain among undergraduate students [27]. In this study, a questionnaire for pain grading was used. CPGS scale showed medical students had grade 1 pain intensity when compared to nonmedical students which mostly reported with grade 0 pain intensity.

According to our research medical students of the final year and 2nd year when compared to first year generally tends to have increased frequency of musculoskeletal pain. This could be due to increasing load of studies, work and stress with each progressing year. However, non-medical students showed no relationship of academic year against musculoskeletal pain. One research also concluded that medical students of all other years when compared with first year incurred an elevated risk for musculoskeletal pain [36].

Our result found an association of carrying bag packs with musculoskeletal pain among both medical and non-medical groups. Heavy college bags on the backs, causing a poor posture and strain especially on neck and lower back. Travelling and standing with bag pack weight can lead to complaints of musculoskeletal pain among students. This finding is approved by study of Heuscher who concluded that increasing usual back weight is associated with increased prevalence of low back pain [37].

Through the results we have found the majority of undergraduate students with musculoskeletal pain had never been seen by doctor or physiotherapist. This result was similar to the research study done by Ayanniah [33]. Our result also reported that those students who had musculoskeletal pain usually relieved their pain by taking rest and pain killers. Positive family history of musculoskeletal pain was found in $44.06 \%$ of medical and $37.44 \%$ of non-medical students. The result was similar to the research concluded somewhere [38].

According to our statistical result about travelling, medical students who travelled about 60 to 180 minutes per day experienced more musculoskeletal pain (52.25\%) compared to non-medical students (40.96\%) daily. About (61.86\%) medical and (59.03\%) non-medical students used public transport for travelling. A study showed that dentists who travelled daily by car experienced more fre- 
quent episodes of neck pain [39]. Heavy lifting and driving are considered to be associated with back pain [40]. Many researches are unable to find a clear association of musculoskeletal pain with travelling.

This study reported that increasing BMI may no longer be a risk factor for musculoskeletal pain. The risk factors such as smoking history of trauma and coffee drinking were also not found to be associated with increased frequency of musculoskeletal pain.

In this study, we have found no relationship of exercise and physical activities like running bicycling swimming with musculoskeletal pain in both medical and non-medical groups. However, a previous study in America showed those who participated in sports activities were less likely affected by musculoskeletal pain of the upper body [41].

Studies have showed the increased prevalence of musculoskeletal pain among undergraduate students. High prevalence of musculoskeletal pain especially neck pain is alarming and demands some serious preventative strategies for both medical and non-medical students. Also, correct guidance should be given to students for sitting and standing postures. Those who are already suffering from musculoskeletal pain, protective measures should be taken to prevent them from disability. A study of Koldas showed different approaches for the treatment of back pain. Exercises are found to be effective in decreasing the intensity of pain [42]. Health programs should be introduced to students which provide awareness regarding the adverse effects of computer use. However, the path of pain development among undergraduate students and their associated contributing factors need further research.

This study has many limitations. The population of this study is limited to undergraduate students. The result of this study may not be suitable for the whole population of students at school and colleges. The data was collected from selected medical and non-medical universities so this could not be representative of all universities students of Pakistan. In this cross sectional study, we could not obtain the follow up data and find the causes and risk factors of the musculoskeletal pain. Recall bias could not be excluded because it was a self-reported questionnaire. Non-medical students may find this questionnaire difficult but we believe medical students understand the terms we used in this survey and also answered accurately. Besides this, the intensity of pain was evaluated by using scale of 0 to 10 , which might vary from the actual severity. Daily records of pain intensity provided by the students could help us in providing the best assessment of pain severity. Association of musculoskeletal pain related to psychological stress has not been evaluated.

\section{Conclusion}

The study concluded that the prevalence of musculoskeletal pain among undergraduate students is truly high. The risk of musculoskeletal pain appeared to be more among medical students. On the contrary medical students have shown no association of studying for long hours and use of computer/laptop with muscu- 
loskeletal pain when compared to non-medical students. This might be due to the fact that medical students are more aware and conscious about their health and sitting postures. This study has given a useful insight into the matter of musculoskeletal pain among undergraduate students. Thinking about the risk factors and avoiding them may lead to lower incidence of this pain. More studies should be done to know contributing factors of musculoskeletal pain among undergraduate students.

\section{References}

[1] Musculoskeletal Pain. http://www.aped-dor.org/images/FactSheets/DorMusculoEsqueletica/en/Musculosk eletalPain.pdf

[2] Acute Musculoskeletal Pain. https://s3.amazonaws.com/rdcms-iasp/files/production/public/Content/ContentFol ders/GlobalYearAgainstPain2/MusculoskeletalPainFactSheets/AcutePain_Final.pdf

[3] Grichnik, K.P. and Ferrante, F.M. (1991) The Difference between Acute and Chronic Pain. The Mount Sinai Journal of Medicine, 58, 217-220.

[4] Mirbod, S.M., Yoshida, H., Miyamoto, K., Miyashita, K., Inaba, R. and Iwata, H. (1995) Subjective Complaints in Orthopedists and General Surgeons. International Archives of Occupational and Environmental Health, 67, 179-186.

[5] Dyrbye, L.N., Thomas, M.R. and Shanafelt, T.D. (2006) Systematic Review of Depression, Anxiety, and Other Indicators of Psychological Distress among US and Canadian Medical Students. Academic Medicine, 81, 354-373. https://doi.org/10.1097/00001888-200604000-00009

[6] Jagsi, R., Shapiro, J. and Weinstein, D.F. (2005) Perceived Impact of Resident Work Hour Limitations on Medical Student Clerkships: A Survey Study. Academic Medicine, 80, 752-757. https://doi.org/10.1097/00001888-200508000-00011

[7] Woolf, A.D. and Pfleger, B. (2003) Burden of Major Musculoskeletal Conditions. Bulletin of the World Health Organization, 81, 646-656.

[8] Kamper, S.J., Henschke, N., Hestbaek, L., Dunn, K.M. and Williams, C.M. (2016) Musculoskeletal Pain in Children and Adolescents. Braz. Journal of Physical Therapy, 20, 275-284.

[9] Reme, S.E., Dennerlein, J.T., Hashimoto, D. and Sorensen, G. (2012) Musculoskeletal Pain and Psychological Distress in Hospital Patient Care Workers. Journal of Occupational Rehabilitation, 22, 503-510. https://doi.org/10.1007/s10926-012-9361-5

[10] Jørgensen, M.B., Korshøj, M., Lagersted-Olsen, J., Villumsen, M., Mortensen, O.S., Skotte, J., Søgaard, K., Madeleine, P., Thomsen, B.L. and Holtermann, A. (2013) Physical Activities at Work and Risk of Musculoskeletal Pain and Its Consequences: Protocol for a Study with Objective Field Measures among Blue-Collar Workers. BMC Musculoskeletal Disorders, 14, 213. https://doi.org/10.1186/1471-2474-14-213

[11] Bao, S., Winkel, J. and Shahnavaz, H. (2000) Prevalence of Musculoskeletal Disorders at Workplaces in the People's Republic of China. International Journal of Occupational Safety and Ergonomics, 6, 557-574. https://doi.org/10.1080/10803548.2000.11076472

[12] Al Saleh, J., Sayed, M.E., Monsef, N. and Darwish, E. (2016) The Prevalence and the Determinants of Musculoskeletal Diseases in Emiratis Attending Primary Health Care Clinics in Dubai. Oman Medical Journal, 31, 117-123. 
https://doi.org/10.5001/omj.2016.23

[13] Slater, H., Jordan, J.E., Chua, J., Schütze, R., Wark, J.D. and Briggs, A.M. (2016) Young People's Experiences of Persistent Musculoskeletal Pain, Needs, Gaps and Perceptions about the Role of Digital Technologies to Support Their Co-Care: A Qualitative Study. BMJ Open, 6, e014007. https://doi.org/10.1136/bmjopen-2016-014007

[14] Alshagga, M.A., Nimer, A.R., Yan, L.P., Ibrahim, I.A., Al-Ghamdi, S.S. and Al-Dubai, S.A. (2013) Prevalence and Factors Associated with Neck, Shoulder and Low Back Pains among Medical Students in a Malaysian Medical College. BMC Research Notes, 6, 244. https://doi.org/10.1186/1756-0500-6-244

[15] Moroder, P., Runer, A., Resch, H. and Tauber, M. (2011) Low Back Pain among Medical Students. Acta Orthopaedica Belgica, 77, 88-92.

[16] Nyland, L.J. and Grimmer, K.A. (2003) Is Undergraduate Physiotherapy Study a Risk Factor for Low Back Pain? A Prevalence Study of LBP in Physiotherapy Students. BMC Musculoskeletal Disorders, 4, 22. https://doi.org/10.1186/1471-2474-4-22

[17] Smith, D.R., Wei, N., Ishitake, T. and Wang, R.S. (2005) Musculoskeletal Disorders among Chinese Medical Students. The Kurume Medical Journal, 52, 139-146. https://doi.org/10.2739/kurumemedj.52.139

[18] Jones, G.T. and Macfarlane, G.J. (2005) Epidemiology of Low Back Pain in Children and Adolescents. Archives of Disease in Childhood, 90, 312-316. https://doi.org/10.1136/adc.2004.056812

[19] Smith, D.R. and Leggat, P.A. (2007) Prevalence and Distribution of Musculoskeletal Pain among Australian Medical Students. Journal of Musculoskeletal Pain, 15, 39-46. https://doi.org/10.1300/J094v15n04_05

[20] Gharib, N.M. and Hamid, N.S. (2013) Prevalence of Mechanical Neck Pain in Taif University Female Students: A Survey Study. Journal of American Science, 9, 347-354.

[21] Leggat, P.A., Smith, D.R. and Clark, M.J. (2008) Prevalence and Correlates of Low Back Pain among Occupational Therapy Students in Northern Queensland. Canadian Journal of Occupational Therapy, 75, 35-41. https://doi.org/10.2182/cjot.07.014

[22] Aggarwal, N., Anand, T., Kishore, J. and Ingle, G.K. (2013) Low Back Pain and Associated Risk Factors among Undergraduate Students of a Medical College in Delhi. Education for Health, 26, 103-108. https://doi.org/10.4103/1357-6283.120702

[23] Yunn, H.T., Nadamurni, N.U. and Wen, P.S. (2013) Prevalence and Risk Factors of Neck Pain among Medical and Health Sciences Undergraduate Students in Universiti Tunku Abdul Rahman (Utar): A Cross-Sectional Study. Doctoral Dissertation, UTAR.

[24] Hafeez, K., Memon, A.A., Jawaid, M., Usman, S., Usman, S. and Haroon, S. (2013) Back Pain-Are Health Care Undergraduates at Risk? Iranian Journal of Public Health, 42, 819-825.

[25] Kuorinka, I., Jonsson, B., Kilbom, A., Vinterberg, H., Biering-Sørensen, F., Andersson, G. and Jørgensen, K. (1987) Standardised Nordic Questionnaires for the Analysis of Musculoskeletal Symptoms. Applied Ergonomics, 18, 233-237. https://doi.org/10.1016/0003-6870(87)90010-X

[26] Von Korff, M., Ormel, J., Keefe, F.J. and Dworkin, S.F. (1992) Grading the Severity of Chronic Pain. Pain, 50, 133-149. https://doi.org/10.1016/0304-3959(92)90154-4 
[27] Kanchanomai, S., Janwantanakul, P., Pensri, P. and Jiamjarasrangsi, W. (2011) Risk Factors for the Onset and Persistence of Neck Pain in Undergraduate Students: 1-Year Prospective Cohort Study. BMC Public Health, 11, 566. https://doi.org/10.1186/1471-2458-11-566

[28] Hoy, D.G., Protani, M., De, R. and Buchbinder, R. (2010) The Epidemiology of Neck Pain. Best Practice \& Research Clinical Rheumatology, 24, 783-792. https://doi.org/10.1016/j.berh.2011.01.019

[29] Niemi, S., Levoska, S., Kemilä, J., Rekola, K. and Keinänen-Kiukaanniemi, S. (1996) Neck and Shoulder Symptoms and Leisure Time Activities in High School Students. Journal of Orthopaedic \& Sports Physical Therapy, 24, 25-29. https://doi.org/10.2519/jospt.1996.24.1.25

[30] Niemi, S.M., Levoska, S., Rekola, K.E. and Keinänen-Kiukaanniemi, S.M. (1997) Neck and Shoulder Symptoms of High School Students and Associated Psychosocial Factors. Journal of Adolescent Health, 20, 238-242. https://doi.org/10.1016/S1054-139X(96)00219-4

[31] Smith, D.R. and Leggat, P.A. (2004) Musculoskeletal Disorders among Rural Australian Nursing Students. Australian Journal of Rural Health, 12, 241-245. https://doi.org/10.1111/j.1440-1854.2004.00620.x

[32] Radcliffe, C. and Lester, H. (2003) Perceived Stress during Undergraduate Medical Training: A Qualitative Study. Medical Education, 37, 32-38. https://doi.org/10.1046/j.1365-2923.2003.01405.x

[33] Ayanniyi, O., Mbada, C.E. and Iroko, O.P. (2010) Neck Pain Occurrence and Characteristics in Nigerian University Undergraduates. TAF Preventive Medicine Bulletin, 9, 167-174.

[34] Rose, K. (2000) The Effect of Neck Pain and Headaches on the Academic Performance of College Students. Journal of the Neuromusculoskeletal System, 8, 118-122.

[35] Rajagopal, V., Rosli, R.M., Rintai, P., Rustim, N., Benadus, R. and Usai, W. (2012) The Prevalence of Computer-Related Musculoskeletal Pain among College Students: A Cross-Sectional Study. American Journal of Medicine, 3, 33-36. https://doi.org/10.3844/amjsp.2012.33.36

[36] Falavigna, A., Teles, A.R., Mazzocchin, T., de Braga, G.L., Kleber, F.D., Barreto, F., Santin, J.T., Barazzetti, D., Lazzaretti, L., Steiner, B. and Beckenkamp, N.L. (2011) Increased Prevalence of Low Back Pain among Physiotherapy Students Compared to Medical Students. European Spine Journal, 20, 500-505. https://doi.org/10.1007/s00586-010-1646-9

[37] Heuscher, Z., Gilkey, D.P., Peel, J.L. and Kennedy, C.A. (2010) The Association of Self-Reported Backpack Use and Backpack Weight with Low Back Pain among College Students. Journal of Manipulative and Physiological Therapeutics, 33, 432-437. https://doi.org/10.1016/j.jmpt.2010.06.003

[38] Frymoyer, J.W., Pope, M.H., Clements, J.H., Wilder, D.G., MacPherson, B. and Ashikaga, T. (1983) Risk Factors in Low-Back Pain. An Epidemiological Survey. The Journal of Bone and Joint Surgery. American Volume, 65, 213-218. https://doi.org/10.2106/00004623-198365020-00010

[39] Ijaz, A., Khan, I., Ahmed, A. and Sadiq, S. (2016) Frequency of Neck Pain among Dentists. Pakistan Orthodontic Journal, 8, 89-93.

[40] Al-Otaibi, S.T. (2015) Prevention of Occupational Back Pain. Journal of Family \& Community Medicine, 22, 73-77. https://doi.org/10.4103/2230-8229.155370

[41] Katz, J.N., Amick, B.C., Carroll, B.B., Hollis, C., Fossel, A.H. and Coley, C.M. (2000) 
Prevalence of Upper Extremity Musculoskeletal Disorders in College Students. The American Journal of Medicine, 109, 586-588.

https://doi.org/10.1016/S0002-9343(00)00538-6

[42] Doğan, Ş.K., Tur, B.S., Kurtaiş, Y. and Atay, M.B. (2008) Comparison of Three Different Approaches in the Treatment of Chronic Low Back Pain. Clinical Rheumatology, 27, 873-881. https://doi.org/10.1007/s10067-007-0815-7 